\title{
Eye Injuries among Road Traffic Accident Victims in Ogun State, Nigeria
}

\author{
HA Ajibode, ${ }^{1}$ LOA Thanni, ${ }^{2}$ OO Onabolu, ${ }^{1}$ OT Bodunde, ${ }^{1}$ TO Otulana ${ }^{1}$ \\ ${ }^{1}$ Department of Ophthalmology, Obafemi Awolowo College of Health Sciences (OACHS), Olabisi Onabanjo University, Sagamu, \\ Nigeria \\ ${ }^{2}$ Department of Orthopaedics and Trauma, Obafemi Awolowo College of Health Sciences (OACHS), Olabisi Onabanjo University, \\ Sagamu, Nigeria
}

\section{SUMMARY}

Aim: To investigate the types of eye injuries seen among road traffic accident (RTA) victims managed at a referral hospital in Ogun State, Nigeria.

Materials and Method: All RTA victims who presented at Olabisi Onabanjo University Teaching Hospital (OOUTH) between July 2004 and June 2005; their eyes were examined by an ophthalmologist for any form of injury. The biodata, cause and type of eye injury, cause of accident, position of victim in the vehicle, use of seat belt by victim, and treatment offered were documented using a questionnaire.

Results: Thirty-five (2.7\%) of the RTA victims (1314) during the study period had various forms of eye injury. The majority were male $(65.7 \%) ; 80 \%$ were between 20 and 40 years. The victims included 7 technical workers $(20 \%) ; 6$ students (17.1\%); 5 traders (14.3\%); 5 office workers (14.3\%); and 5 drivers $(14.3 \%)$. Only $24 \%$ of the drivers and $8 \%$ of front seat passengers had used a seat belt. The majority of the victims, $23(65.7 \%)$, had a combination of extraocular and anterior segment injuries. Lid injury was the most common extraocular injury 29 (90.6\%), followed by laceration $(34.4 \%)$, oedema $(30.2 \%)$ and bruising $(25 \%)$; while the most common injury of the anterior segment was subconjunctival haemorrhage 23 (85.2\%). Most of the patients, $28(80 \%)$, presented within 24 hours of injury.

Conclusions: The majority of eye injuries from RTAs seen at OOUTH, Sagamu were mild and mainly found in the extraocular and anterior segments of the eye.

Key words: eye injury, road traffic accidents, anterior segment, extraocular segment, posterior segment

\section{INTRODUCTION}

Evidence suggests that the present and projected global burden of road-traffic injuries is disproportionately borne by countries that can least afford to meet the health service, economic, and societal challenges posed. ${ }^{1}$ Although the evidence on which these estimates were based remains somewhat precarious in view of the limited data systems in most low-income and middle-income countries (as per the classification on the World Bank website), these projections highlight the essential need to address road-traffic injuries as a public-health priority. ${ }^{1}$ In 2002, an estimated 1.2 million people were killed and 50 million injured in road-traffic crashes worldwide, costing the global community about US\$518 billion. $^{2}$

Road traffic accidents (RTAs) are common everyday occurrences in Nigeria, and Ogun State is not an exception. In fact the state is vulnerable as a number of major state and federal interstate highways cross the state. Two major expressways link at Sagamu, a town where the state's tertiary referral eye centre (this study's centre) is located.

Road traffic accidents are well known causes of ocular morbidity and blindness worldwide ${ }^{3}$. Among all causes of eye injuries, RTA was previously superseded by farm injuries, assault, technical work and domestic injuries. ${ }^{4,5,6,7,8,9}$ However, since the 1960s and 1970s, RTA has taken over as the most common cause of serious eye injury, with car occupants suffering penetrating injuries caused by broken windscreen glass. ${ }^{10}$ These were often bilateral and commonly blinding. The introduction of laminated windscreens and the seatbelt law virtually eliminated this problem. ${ }^{4,10,11,12}$

Eye injuries associated with RTA can sometimes pose diagnostic difficulties, as patients with reduced consciousness levels may not report visual symptoms, and assessment of the eye can be awkward in a supine patient. ${ }^{13}$ Also, it may not be possible to see the eye ball properly at the initial stage in patients with facial injuries, because of periorbital haematomas and swelling. ${ }^{13,14}$

Ocular injury from road traffic accidents may be mild, moderate, or severe, and affect the eyelids, lacrimal canaliculi, orbital wall, conjunctiva, cornea, sclera and the extraocular muscles. ${ }^{3,11}$ There may be prolapse of uveal tissue, vitreous loss, traumatic cataract, retinal detachment, vitreous haemorrhage, choroidal rupture, optic nerve avulsion or a ruptured globe in serious cases. ${ }^{3}$ 
Eye injuries can result in some visual loss, thus creating substantial costs both to the victim and the society. Even minor eye injuries can cause considerable morbidity and time loss from work. ${ }^{10,11}$ Thus, there is an urgent need for more publicity on preventive measures to reduce eye injuries. This study is an attempt to document and analyse recent trends on damage to the eye caused by road traffic accidents in Ogun State, Nigeria.

The number of studies on eye injuries from RTAs in Nigeria are scanty. Thus, this study hopes to add to the extant literature on eye injuries caused by RTAs, and highlight the peculiar situation in Ogun State, Nigeria.

\section{MATERIALS AND METHOD}

The Accident and Emergency Unit of OOUTH, Sagamu receives trauma cases 24 hours a day. The centre is the main referral hospital for ocular injuries in Ogun State. A prospective observational study was done, during which all RTA victims who presented at the centre between July 2004 and June 2005, with any form of eye injury, had their eyes examined by an ophthalmologist with the Snellen's chart or the non literate E-chart, pen torch, direct ophthalmoscope (or indirect ophthalmoscope when necessary), and slit lamp.

The relevant data were collected using a questionnaire. The questionnaire sought information on age, sex, occupation, time of injury, position of victim in the vehicle at the time of the accident, use of seatbelt by the driver and passengers, time of presentation, injuries sustained including the specific diagnosis of eye involvement. The types of treatment given were also recorded.

The data were analyzed with Epi-Info version 2002 (Centre for Disease Control Atlanta, USA). The results were presented as frequencies and percentages. The relevant OOUTH Ethical Committee's approval was obtained. Consent was obtained from victims or relatives as necessary.

\section{RESULTS}

One thousand, three hundred and fourteen RTA patients $(\mathrm{n}=1314)$ were treated at OOUTH during the study period; only $35(2.7 \%)$ had a form of eye injury and this constituted $31.3 \%$ of all eye injuries $(n=112)$ seen during the study period.

\section{Characteristics of RTA victims with eye injuries}

Out of the 35 patients with eye injury, $23(65.7 \%)$ were male and $12(34.3 \%)$ were female. The majority, 25 (71.5\%) were aged between 20 and 40 years (see table1), with a mean age of 32.4 years. Twenty-five of the victims were passengers $(71.4 \%)$; 6 were drivers $(17.1 \%)$; and 4 were pedestrians $(11.5 \%)$.

Table 2 shows the occupations of the victims. The more common occupations were: technical worker $7(20 \%)$, student $6(17.1 \%)$, trader $5(14.3 \%)$, clerical worker $5(14.3 \%)$, and driver $5(14.3 \%)$. The positions of the passengers in the affected vehicles were recorded; $17(74 \%)$ were in the backseat, $6(24 \%)$ in the front seat. Only $6(24 \%)$ of the drivers and $2(8 \%)$ front seat passengers of the 25 that responded were wearing seatbelts at the time of accident.

Table 1. Age and sex distribution of subjects who had eye injuries from RTAs

\begin{tabular}{ccccccc}
\hline & & & \multicolumn{2}{c}{ Male } & \multicolumn{2}{c}{ Female } \\
\cline { 4 - 7 } Age $(\mathrm{yrs})$ & Freq & Per cent & $\mathrm{n}$ & $\%$ & $\mathrm{n}$ & $\%$ \\
\hline $0-10$ & 2 & 5.7 & 1 & 2.9 & 1 & 2.9 \\
$>10-20$ & 0 & 0 & 0 & 0 & 0 & 0 \\
$>20-30$ & 17 & 48.6 & 11 & 31.4 & 6 & 17.1 \\
$>30-40$ & 8 & 22.9 & 6 & 17.1 & 2 & 5.7 \\
$>40-50$ & 5 & 14.3 & 4 & 11.4 & 1 & 2.9 \\
$>50-60$ & 3 & 8.6 & 1 & 2.9 & 2 & 5.7 \\
\hline Total & $\mathbf{3 5}$ & $\mathbf{1 0 0 . 0}$ & $\mathbf{2 3}$ & $\mathbf{6 5 . 7}$ & $\mathbf{1 2}$ & $\mathbf{3 4 . 3}$ \\
\hline
\end{tabular}

Table 2. Occupation of RTA victims with eye injuries

\begin{tabular}{lcc}
\hline Occupation & Frequency & Percent \\
\hline Technical worker & 7 & 20.0 \\
Student & 6 & 17.1 \\
Clerical worker & 5 & 14.3 \\
Driver & 5 & 14.3 \\
Trader & 5 & 14.3 \\
Teacher & 3 & 8.6 \\
Businessman & 2 & 5.7 \\
Housewife & 1 & 2.9 \\
Uniform forces & 1 & 2.9 \\
\hline Total & 35 & 100.0
\end{tabular}

\section{Presentation of victims}

Twenty-eight $(80 \%)$ patients presented within 24 hours of injury; 5 (14.3\%) within a week; 1 (2.9\%) each within 48 hours and a month after the accident. Of the 35 victims, 14 $(42.4 \%)$ presented in the evening, $12(36.4 \%)$ in the afternoon, $5(15.2 \%)$ in the morning and only $2(6.1 \%)$ at night. The presentation time of two of the patients was not recorded.

\section{Nature of injuries sustained}

Most patients sustained extraocular $(n=31)$ and anterior segment $(\mathrm{n}=27)$ injuries as detailed in tables 3 and 4 . A large majority of the victims had a combination of extraocular and anterior segment injuries $23(65.7 \%)$.

The most prevalent extraocular injuries seen were lid injuries $29(90.6 \%)$, comprising laceration $(37.9 \%)$, oedema $(33.3 \%)$ and bruising (24.2\%); while anterior segment injuries included subconjunctival haemorrhage 23 (85.2\%). Posterior segment injuries were seen in only two patients, 
and they were commotio retinae and retinal detachment (see tables 3 \& 4).

Table 3. Group of injuries sustained by victims

\begin{tabular}{lcc}
\hline Type of injury groups & Frequency & Per cent \\
\hline Extraocular injury only & 8 & 22.9 \\
Anterior segment only & 2 & 5.7 \\
Posterior segment only & 0 & 0.0 \\
Extraocular+anterior segment & 23 & 65.7 \\
Anterior + posterior segment & 2 & 5.7 \\
\hline TOTAL & $\mathbf{3 5}$ & $\mathbf{1 0 0 . 0}$ \\
\hline
\end{tabular}

Table 4. Specific injury sustained in each eye segment

\begin{tabular}{lcc}
\hline Specific injury & Freq. & Per cent \\
\hline Extraocular & 11 & \\
Eyelid laceration & 10 & 35.5. \\
Eyelid oedema & 8 & 32.3 \\
Eyelid bruising & 1 & 25.9 \\
Retrobulbar haemorrhage & 1 & 3.2 \\
Nerve palsies & 31 & 3.2 \\
\hline Total & 23 & 100.0 \\
\hline Anterior segment & 2 & 85.2 \\
Subconjunctival haemorrhage & 1 & 7.4 \\
Corneal perforation & 1 & 3.7 \\
Corneal abrasion & 27 & 3.7 \\
Scleral perforation & & 100.0 \\
\hline Total & 1 & 50.0 \\
\hline Posterior segment & 1 & 100.0 \\
Commotio retinae & & \\
Retinal detachment & & \\
\hline Total & & 50.0 \\
\hline
\end{tabular}

\section{Treatment received}

The treatment received by victims were medical 20 (57.1\%), surgical $3(8.6 \%)$ in the form of lid or corneoscleral laceration repair, and a combination of both in $12(34.3 \%)$ cases.

\section{DISCUSSION}

In this study, only a small proportion of road traffic accident patients had eye injuries $(2.7 \%)$ but $31.3 \%$ of all eye injuries were from RTA. This is similar to findings in many other studies. $^{3,4,10}$

There was a preponderance of men (1.92:1) among the victims as reported in many other eye injury studies worldwide. ${ }^{1,3,4,5,6,7,8,9,12}$ The age distribution showed that a majority of the patients are in their economically productive years, i.e. 20 to 40 years $(71.5 \%)$, which corresponds to findings in similar studies worldwide. . $3,4,5,6,9,12,15,16^{-1}$
The majority of victims were passengers $(71.4 \%)$ as expected, since most commercial vehicles have many passengers. The occupations of the victims, viz: technical worker, student, trader, office worker, and driver, clearly show that these passengers are actively involved in the workforce and they need to be mobile to pursue their means of livelihood. ${ }^{3,7,8,9}$ This has serious socioeconomic implications for the society, thus, the prevention of RTAs and eye injuries will impact positively on the economy.

Most of the passengers who were involved in RTAs and who had eye injuries were in the back seat (68\%); while $24 \%$ were front seat passengers. This is in contrast to findings in the developed world ${ }^{4,10,11,12,17}$ where the head-on collision is a common cause of road crashes with ocular injuries to front seat passengers from shattered glass. This may be because more passenger seats are located behind the driver; moreover, most accidents probably somersault and swerve off-the-road. It will be interesting to know whether there is any difference in the type and severity of injuries sustained by front seat passengers compared to back seat and others, however, this goes beyond the scope of this study, because of the small number and short period involved.

However, the result from the 25 victims that responded showed that only $6(24 \%)$ drivers and $2(8 \%)$ front seat passengers were using seatbelts at the time of the accident. Negrel and Thylefors reported that many studies have found that over $85 \%$ of RTA eye injuries were a consequence of passengers not wearing seatbelts. ${ }^{18}$ This was confirmed by findings that RTA and eye injuries from them reduced drastically after the introduction of the seatbelt law in Europe. ${ }^{4,10,11,19,20}$ From a study done in the US, ${ }^{12}$ it was found that seatbelt use is the most effective means of occupant protection against motor-vehicle-collision (MVC)-related eye injury. Therefore, if seatbelt compliance increases it will help in reducing eye injuries among RTA victims.

The majority of RTA victims $(28=80 \%)$ presented within 24 hours of injury. This is similar to the Libyan study ${ }^{3}$ where $73 \%$ presented within 24 hours. This was probably made possible because of good coverage of the major roads by the Federal Road Safety Corps (FRSC) and officers of the Ogun State Accident Services (OGSAS) who assisted most of the victims to the health centre. Most patients presented during the day, i.e., evenings (42.4\%), afternoons (36.4\%) and mornings $(15.2 \%)$. This ensures prompt and appropriate treatment and guarantees best services as most specialists are easily accessible during the day.

The types of eye injuries sustained by victims indicate that most of them (i.e. 65.7\%) involved extraocular and anterior segments. Most of these injuries were mild and rarely threatened vision. They included subconjunctival haemorrhage, lid laceration, lid oedema, and lid bruising. This is in keeping with findings in most studies on eye injuries following RTA, especially after laminated windscreens became the norm for vehicles 
worldwide. ${ }^{3,4,9,10,11,19,20}$ However, even mild eye injuries can affect the available man hours of victims at their work.

The type of treatment received showed that 20 (57.1\%) needed only medication, while $12(34.3 \%)$ required both medication and surgery and only $3(8.6 \%)$ had mainly surgery. This confirms the predominance of mild injuries in the study.

\section{CONCLUSIONS}

Road traffic accidents causing mild eye injuries commonly involve men in their productive years of life. The victims in this study presented at the hospital earlier than indicated in a previous study conducted at the same centre. ${ }^{7}$ Most of them required only medical treatment; those requiring surgery were few. There is a need to study the specific implications of poor traffic law compliance and the position of passengers in vehicles who sustain eye injuries during RTAs. Poor compliance to the seatbelt law needs urgent attention to reduce eye injuries during RTAs.

\section{REFERENCES}

1. Ameratunga S, Hijar M, Norton R. Road-traffic injuries: Confronting disparities to address a global-health problem. Lancet 2006; 367: 1533-40.

2. Peden M, Scurfield R, Sleet D, et al, eds. World report on road traffic injury prevention. Geneva: World Health Organization, 2004. http:// www.who. int/ world-healthday/2004/infomaterials/world_ report/ en/summary_en_ rev.pdf (accessed March 2, 2006).

3. Shtewi ME, Shishko MN, Purohit GK. Road traffic accidents and ocular trauma: Experience at Tripoli Eye Hospital, Libya. J Comm Eye Health 1999; 12(29): 11-2.

4. Mackay GN. Incidence of trauma to the eyes of car occupants. Trans Ophthalmol Soc UK 1975; 95: 311-314.

5. Ilsar M, Chirambo M, Belkin M. Ocular injuries in Malawi. $\mathrm{Br}$ J Ophthalmol 1982; 66(2): 145-8.
6. Adefule-Ositelu AO, Soetan II, Akinsola FB. Ocular trauma in Lagos. West Afr J Med 1996; 15(4): 210-4.

7. Onabolu OO. Visual loss in ocular trauma. Nig J Ophthal 1992; 2: 12-24.

8. Ajaiyeoba AI. Ocular injuries in Ibadan. Nig J Ophthal 1995; 3(2): 18-20.

9.. Macewen CJ. Eye injuries: A prospective survey of 5671 cases. Br J Ophthalmol 1999;83: 933-936.

10. Vernon SA, Yorston DB. Incidence of ocular injuries from road accidents after introduction of seat belt legislation. J R Soc Med 1984; 77(3): 198-200.

11. Johnston $\mathrm{PB}$, Armstrong MF. Eye injuries in Nothern Ireland two years after seat belt. $\mathrm{Br}$ J Ophthalmol 1986; 70: 460-2.

12.. McGwin G, Owsley C. Risk factors for motor vehicle collisionrelated eye injuries. Arch Ophthalmol 2005; 123: 89-95.

13. Guly CM, Guly HR, Bouamra O, Gray RH, Lecky FE. Ocular injuries in patients with major trauma. Emerg Med J 2006; 23: 915-7.

14. Ugboko VI, Udoye C, Olateju SO, Amole AO. Blindness and visual impairment from severe midface trauma in Nigerians. Int J Oral Maxillofac Surg 2006; 35(2): 127-31.

15. Canavan YM, O'Flaherty MJ, Archer DB, Elwood JH. A 10-year survey of eye injuries in Nothern Ireland, 1967-76. Br J Ophthalmol 1980; 64(8): 618-25.

16. Schrader WF. Open globe injuries: Epidemiological study of two eye clinics in Germany, 1981-1999. Croat Med J 2004; 45(3): 268-74.

17. Koval R, Teller J, Belkin M, et al. The Israeli ocular injury study - A nationwide collaborative study. Arch Ophthalmol 1988; 106: 776-780.

18 Negrel A-D, Thylefors B. The global impact of eye injuries. Ophthalmic Epidemiology 1998; 5: 143-69.

19. Cole MD, Clearkin L, Dabbs T, Smerdon D. The seat belt law and after. Br J Ophthalmol 1987; 71: 436-40.

20. Hogeweg M. Car seatbelts. J Comm Eye Health 2000; 13(36): 62. 